Chem. Chem. Technol., 2021,

Vol. 15, No. 4, pp. 536-542

Chemistry

\title{
MONOMOLECULAR FILMS OF ORGANIC DIACYL DIPEROXIDES ON THE INTERFACE OF THE PHASES WATER-AIR
}

\author{
Volodymyr Dutka ${ }^{1}{ }^{凶}$, Olena Aksimentyeva ${ }^{1}$, Yaroslav Kovalskyi ${ }^{1}$, \\ Natalya Oshchapovska ${ }^{1}$
}

https://doi.org/10.23939/chcht15.04.536

\begin{abstract}
Monomolecular films of diacyl diperoxides at the water-air phase interface have been studied. Their behaviour is influenced by the structure of the molecule and the solvent. The numerical values of the areas of molecules that are extrapolated to zero pressure are different, which indicates a different conformation of the molecules in the monolayer. The conformational states of diperoxides were calculated by quantum chemical methods. Experimental data and quantum chemical calculations are consistent with each other.
\end{abstract}

Keywords: diperoxides, monomolecular layers, quantumchemical calculation, conformation.

\section{Introduction}

Polyfunctional peroxide compounds are successfully used for obtaining polymer-mineral composites, polymers with special properties, nanomaterials, and processing of various surfaces [1]. Peroxide initiators are widely used in the processes of emulsion and suspension polymerization [2]. Therefore, for the successful use of polyfunctional peroxides information about their behavior at the interface of phases is required.

One of the widely used methods for studying the behavior of the substances on the air-water interface is the preparation of monomolecular films [3]. This method opens up the ability to control the structure of materials, to organize and orientate the molecules in monolayers, providing the maximum efficiency of the chemical reactions [4].

The preparation of Langmuir films is associated with the formation of monolayers of surfactants on the interface between the liquid and the air, when spreading droplets of the solution along the surface of the water. Many insoluble amphiphilic substances in the water represent polar molecules of organic substances

\footnotetext{
${ }^{1}$ Ivan Franko National University of Lviv,

6, Kyryla \& Mefodia St., Lviv, 79005, Ukraine

vdutka@ukr.net

(C) Dutka V., Aksimentyeva O., Kovalskyi Y., Oshchapovska N., 2021
}

containing the hydrophilic part - "head" and a hydrophobic part - "tail", capable of spreading over the water surface by a monomolecular layer. Investigating the dependence of the surface pressure on the monolayer area, Langmuir found the existence of various phase states in such films. Monomolecular films of insoluble amphiphilic substances on the surface of the liquid were called Langmuir films $[4,5]$. A classic method for obtaining Langmuir films is the use of a special cuvette with a barrier, which serves to regulate surface pressure by changing the area covered by the surfactant. At low pressure, the molecules are in a state of "two-dimensional gas". Increasing the pressure due to bias of the barrier leads to the formation of ordered monolayers of condensed liquid and solid state.

In the present work the monomolecular films of diacylic diperoxide initiators formed on the aqueous surface due to the presence of hydrophilic and hydrophobic components in the molecule is studied. The surface pressure of monolayers of diperoxide compounds was determined. The heterogeneous processes are occurring with the participation of these compounds and the results of this study may be useful for predicting the behavior of diperoxide on the phase boundary.

\section{Experimental}

The diperoxides (DP) were synthesized by the interaction of corresponding peroxycarboxylic acids and the dichloride of dicarboxylic acids in the presence of pyridine [6]. The scheme of the reaction:

$$
\begin{aligned}
& 2 \mathrm{CH}_{3}-\left(\mathrm{CH}_{2}\right)_{\mathrm{m}}-\mathrm{C}(\mathrm{O}) \mathrm{OOH}+\mathrm{Cl}-\mathrm{C}(\mathrm{O})-\left(\mathrm{CH}_{2}\right)_{\mathrm{n}}-\mathrm{C}(\mathrm{O}) \mathrm{Cl} \rightarrow \\
& \rightarrow \mathrm{CH}_{3}-\left(\mathrm{CH}_{2}\right)_{\mathrm{m}}-\mathrm{C}(\mathrm{O}) \mathrm{OO}(\mathrm{O}) \mathrm{C}-\left(\mathrm{CH}_{2}\right)_{\mathrm{n}}-\mathrm{C}(\mathrm{O}) \mathrm{OO}(\mathrm{O}) \mathrm{C}- \\
& \left(\mathrm{CH}_{2}\right)_{\mathrm{m}}-\mathrm{CH}_{3}+2 \mathrm{HCl}
\end{aligned}
$$

The diperoxides were washed with water and recrystallized. The purity of synthesized peroxides, as determined by iodometric analysis [7], was at least 98.5-99.5\%.

The investigated diperoxide compounds have different carboxylic $\left(R_{1}\right)$ and dicarboxylic $\left(R_{2}\right)$ radicals of varying sizes and flexibility. The general formula of DP is: 


$$
\begin{gathered}
\mathrm{CH}_{3}-\left(\mathrm{CH}_{2}\right)_{m}-\mathrm{C}(\mathrm{O})-\mathrm{O}-\mathrm{O}-\mathrm{C}(\mathrm{O})-\left(\mathrm{CH}_{2}\right)_{n}-\mathrm{C}(\mathrm{O})-\mathrm{O}-\mathrm{O}- \\
\mathrm{C}(\mathrm{O})-\left(\mathrm{CH}_{2}\right)_{m}-\mathrm{CH}_{3}
\end{gathered}
$$

where $n=2, m=8$ (I); $n=3, m=8$ (II); $n=4, m=0$ (III); $n=4$, $m=3(\mathbf{I V}) ; n=4, m=8(\mathbf{V}) ; n=8, m=0$ (VI); $n=8 ; m=1$ (VII); $n=8, m=8$ (VIII); $\mathrm{C}_{6} \mathrm{H}_{5}, n=4$ (IX); $m=8, n-\mathrm{C}_{6} \mathrm{H}_{4}(\mathbf{X}) ; n=4$, $\mathrm{m}=5(\mathbf{X I})$

The monomolecular films of DP of different types were formed. To measure the surface pressure of monomolecular films, a vertical weight was used, the basis of which was the principle of the action of the Langmuir surface weight [8]. The solvent effects on the area of the peroxide molecules in their monolayer were studied. The surface pressure $(\pi, \mathrm{mN} / \mathrm{m})$ of the peroxides monolayers was measured using a vertical installation. Solutions of peroxides in a certain solvent were applied to the aqueous surface of the cuvette in the size from 60 to $16.5 \mathrm{~cm}$. The monolayer was compressed on the surface of the water by a Teflon barrier. All measurements were made at the compressive speed of $1 \mathrm{~mm} / \mathrm{s}$ and constant temperature of $293 \pm 0.5 \mathrm{~K}$. To obtain a monomolecular layer, a drop of a solution of peroxide from a micropipette was applied on a clean aqueous surface. The monolayer was compressed after $10 \mathrm{~min}$. Before applying the monolayer, the water surface was updated by moving the Teflon barrier on it. In all cases, the error did not exceed $\pm 5 \%$ relative in determining the numerical value of the area extrapolated to zero pressure.

Surface pressure isotherms were obtained as a dependence of the pressure $\pi$ on the area occupied by one molecule of the test substance $S$. The number of monomer units $x$ of the substance in the monolayer was determined by the formula:

$$
x=N \cdot g / M
$$

where $M$ is the molecular weight of the monomer unit; $N$ is Avogadro's number; $g$ is the amount of substance on the substrate surface, $g$.

Knowing the number of monomer units contained on the surface, the area $S_{m}$ was determined by the formula:

$$
S_{m}=a / x
$$

where $a$ is the surface area of the monolayer; $x$ is the number of monomer units (mole of a substance in a monolayer).

Surface pressure was determined by the formula:

$$
\pi=q \Delta P / b
$$

where $q$ is the gravitational constant, $\mathrm{m} / \mathrm{s}^{2} ; \Delta P$ is a change of load, $\mathrm{g}$; $b$ is a perimeter of the plate, $\mathrm{m}$.

Quantum-chemical calculations for diacylic diperoxides were carried out by the semiempirical program MOPAC2016 [9] with the graphical interface Winmostar [10]. To optimize the geometric structure and calculate the heat of molecular structures formation $\left(\triangle_{f} H^{298}\right)$, energies of the highest occupied $\left(E_{\text {HOMO }}\right)$, and lowest unoccupied $\left(E_{L U M O}\right)$ molecular orbitals, as well as charges on atoms by Mulliken different semiempirical methods, were used.

\section{Results and Discussion}

The surface pressure of monolayers of diperoxide compounds was studied for didecanoyldiperphtalate $(\mathbf{X})$, diacetyldiperadipinate (III), dienanthioyl diperadipinate (XI), and didekanoyldiperadipinate (V) in different organic solvents. The isotherms for the surface of the pressure of studied diperoxides were obtained when applying films from various solvents adduce on Figs. 1-4. The solvent was used when the film was applied to the interface of the water-air. It influenced the nature of the isotherms and the extrapolated values of the areas corresponding to the molecule in the monolayer (Figs. 1-4). The isotherms belong to the condensable type according to their nature [4].

In the diperoxide $\mathbf{X}$, between the peroxide groups there is a flat and not flexible radical $-(\mathrm{O}) \mathrm{C}-\mathrm{C}_{6} \mathrm{H}_{4}-\mathrm{C}(\mathrm{O})-$, so the change in surface pressure during compression of the monomolecular layer is due to the flexibility of the side radicals. The values of the area extrapolated to zero pressure are influenced by the solvent used to apply $\mathbf{X}$ to the phase boundary. The diperoxide compound in a particular solvent is characterized by a certain conformational state. When transferring diperoxide to the surface of the water, this conformational state is partially preserved, which leads to different values of areas extrapolated to zero pressure of the diperoxide molecule in the monolayer. During film compression, different packing of molecules in the monolayer will be ensured, which depends on the nature of the solvent used when applying the peroxide to the phase boundary. Macromolecules III form a phase separation of condensed-type monolayers on the surface. According to the data obtained, the flexibility of the radical between the peroxide groups is negligible. The terminal radicals of III are small, so the surface pressure isotherms have a behavior similar to $\mathbf{X}$.

For diperoxides $\mathbf{X I}$ and $\mathbf{V}$, which are characterized by large radicals $R_{1}$, the character of surface pressure isotherms differs from the behavior of III and $\mathbf{X}$ (Figs. 1-4). At large values of the area attributable to the DP molecule, the monolayer is in the form of a two-dimensional surface gas. The compression of the film leads to a change in the nature of the film. Initially, stretched-liquid films are formed. With further compression, condensed films are formed. Upon reaching the values of the area belonging to the molecule $70-60 \AA^{2}$, judging by the shape of the isotherms, the radical $R_{1}$ is displaced from the plane of the phase separation. For compound XI, the process of displacement from the surface of the lateral radicals $R_{1}$ from the surface of the phase separation depends on the 
nature of the solvent used to apply DP to the phase interface (Fig. 1). In the case of compound $\mathbf{V}$, regardless of the solvent nature, organized displacement of the lateral

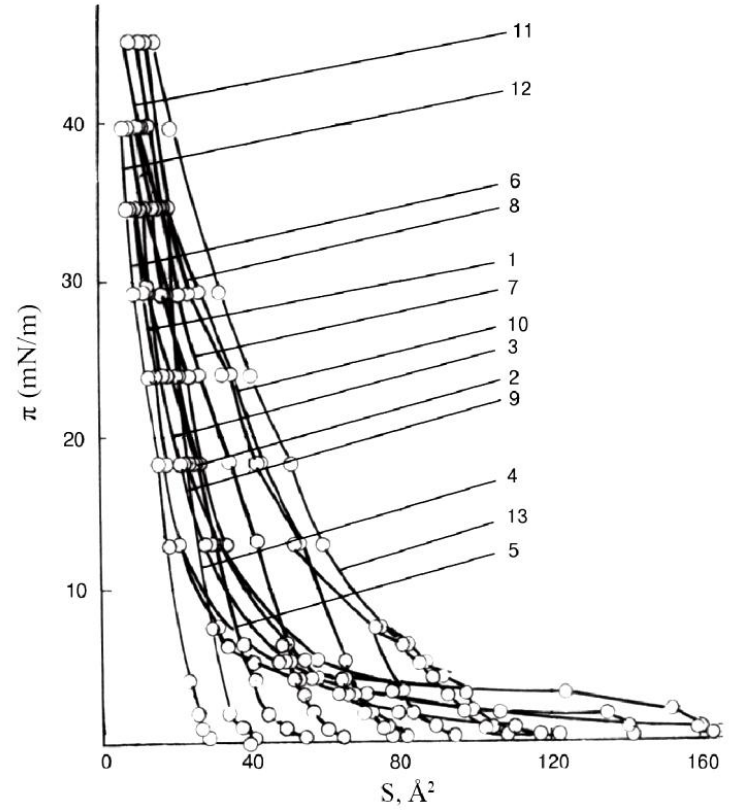

Fig. 1. The isotherms of the surface pressure of XI monolayers when applied from a solvent: 1 - benzene; 2 - toluene; 3 -xylene; 4 -ethylbenzene; 5 - chlorobenzene; 6 - cyclohexane; 7 - chloroform; 8 - tetrachloromethane; 9 - ethyl acetate; 10 butyl acetate; 11 - dioxane; 12 - acetone; 13 - methylethylketone radicals at the surface of the phase interface occurs at the values of the areas belonging to the molecule $50-90 \AA^{2}$ (Fig. 2).

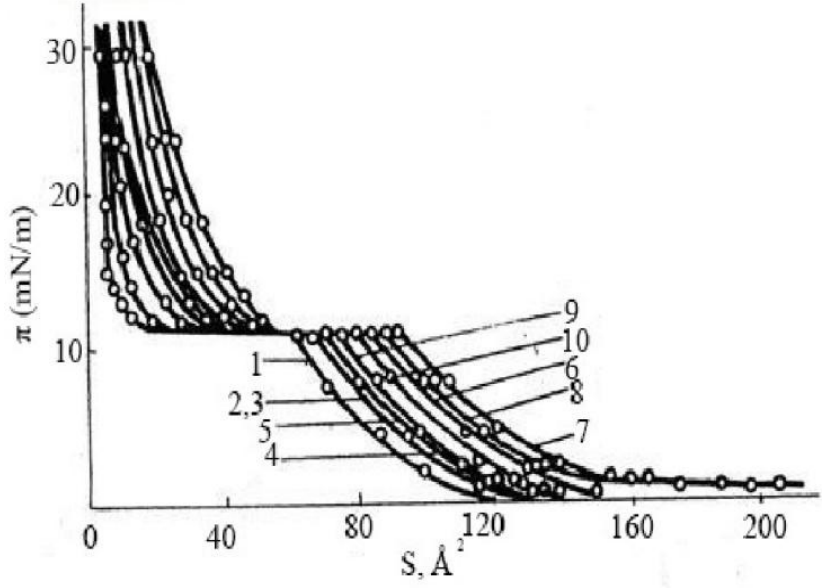

Fig. 2. The surface pressure of isotherms of $\mathbf{V}$ monolayers when applied from a solvent: 1 - benzene; 2 - toluene; 3 -xylene; 4 - ethylbenzene; 5 - chlorobenzene; 6 - cyclohexane; 7 - chloroform; 8 - tetrachloromethane; 9 - ethyl acetate; 10 - butyl acetate

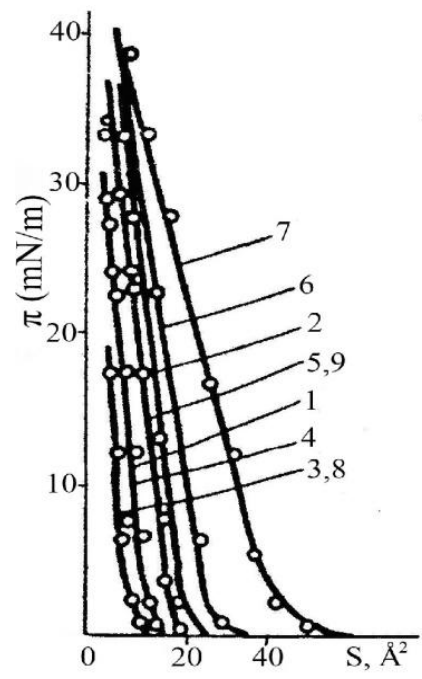

Fig. 3. The isotherms of surface pressure of monolayers of III when applied from a solvent: 1 - benzene; 2 - toluene; 3 -xylene; 4 - ethylbenzene; 5 - cyclohexane; 6 - chloroform; 7 - tetrachloromethane; 8 - ethyl acetate; 9 - butyl acetate

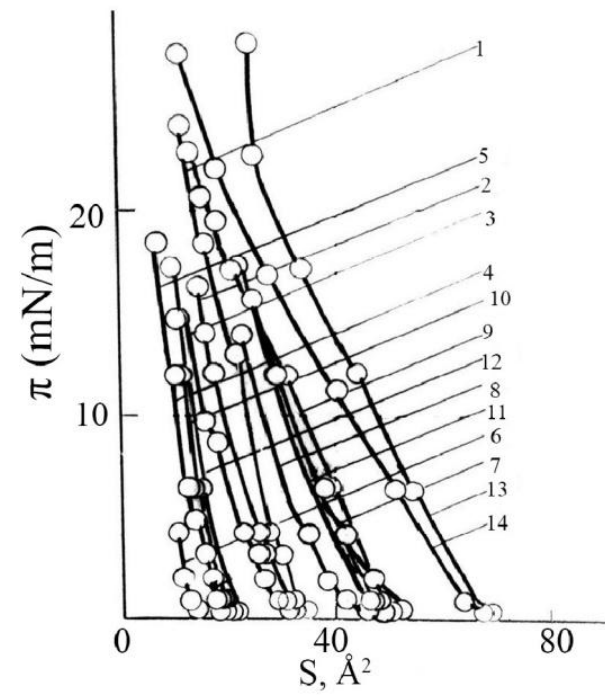

Fig. 4. The isotherms of surface pressure of monolayers of $\mathbf{X}$ when applied from a solvent: 1 - benzene; 2 - toluene; 3 -xylene; 4 - acetone; 5 - methylethyl ketone; 6 - dioxane; 7 - ethyl acetate; 8 - chloroform; 9 - tetrachloroethane; 10 - cyclohexane; 11 - butyl acetate; 12 - methyl acetate; 13 - chlorobenzene; 14 - ethylbenzene 
The isotherms have a different nature [4] according to the obtained data (Figs. 1-4). Diperoxides, which contain radical $R_{2}$, between the $\mathrm{O}-\mathrm{O}$ bonds, the remainder of adipic acid, in the monolayer, behave differently (Figs. 1-3). This indicates the low flexibility of the group $-\left(\mathrm{CH}_{2}\right)_{4}-$ in the peroxide molecule. The isotherms are changing with the increase of the radical $R_{1}$ (Figs. 1, 2). The confirmatory state of the molecule in the monolayer is changing for peroxide $\mathbf{V}$. This indicates the displacement of the radicals $\mathrm{CH}_{3}-\left(\mathrm{CH}_{2}\right)_{8}$ - from the surface of the water (Fig. 2). The monolayers of diperoxide $\mathbf{X}$ are rigid. The radical located in the middle of the molecule - the remainder of phthalic acid - is flat and stiff.

The numerical values of the areas $\left(S_{0}\right)$, which are occupied by the molecules of the studied diperoxides in the monolayer, are given in Table 1. DP III molecules have the smallest areas in the monolayer. The area of the DP XI in the monolayer is slightly smaller than the corresponding values for the DP $\mathbf{V}$. The numerical values of the extrapolated areas for all investigated diperoxides depend on the solvent from which the monolayer was formed. Non-identical numerical values of the areas are corresponding to the diperoxide in the monolayer. It was formed from the soluble solvents and indicated the possible different packaging of the diperoxide oxide molecules in the monolayer. The hydrophilic peroxide groups are on the boundary of the phase separation, whereas the hydrophobic terminal hydrocarbon radicals can be located both in the plane of the section and oriented toward the air phase at high pressures in the monolayer. Since the size of the aliphatic radical between the peroxide groups is small, its effect on the change in the area of the molecule in the monolayer when compressed will be low.

Thus, the experimental results regarding the surface pressure of diacylic peroxides monolayers give information about their behavior at the interface between phases and predict their reactivity in these conditions.
There is a relationship between the values of the areas of peroxide in the monomolecular layer $\left(S_{0}\right)$ and the rate constants of the decomposition $(k)$ of diperoxide $\mathbf{V}$ in the corresponding solvent. Small values of $S_{0}$ correspond to large values of $k$, which indicates the influence of the conformational state of the molecule on the stability of the peroxide group.

Quantum-chemical calculations can give important information on the structure and electronic properties of the studied diperoxides.

Quantum-chemical calculations were carried out using some of the semiempirical methods: AM1, PM3, PM5, PM6, MNDO, and RM1 for the diperoxide IV molecule. The numerical values of the heat of formation of diacylic diperoxide IV $\left(\Delta_{f} \mathrm{H}^{298}\right)$ calculated by semiempirical methods are close to the corresponding values. They were obtained based on thermochemical experiments [11]. The numerical values of $\Delta_{f} H^{298}$ calculated by the PM3 and RM1 best coincide with the experimental data (Table 2). The semiempirical method RM1 has more opportunities compared to others (Table 3). The diperoxide compound $\mathbf{I V}$ is polar one according to the obtained calculations. Its dipole moments $(\mu)$ are calculated by different methods (1.993-6.073 D). The numerical values of the ionization potential $\left(I_{x}\right)$ of diperoxide $\mathbf{I V}$ and the associated energy parameter $E_{\text {НОмо }}$ are close (-11.089 to $-10.717 \mathrm{eV})$. The numerical values of $E_{L U M O}$ vary in the wider range, from -1.133 to $+0.453 \mathrm{eV}$. The numerical values of the total squares of molecules $(S)$ and the volume of molecules $(V)$ are close and depend on the calculation method.

The structure of the investigated diperoxides in the basic state of the molecule is rod-shaped (Fig. 5). All DPs have many conformations at the expense of the hydrocarbon radical flexibility. Different conformational states of the DP molecules are characterized by practically the same energy and can substantially change the dipole moment.

Table 1

The extrapolated values of the areas corresponding to the molecule DPs in a monolayer and rate constants of the DP V decomposition in different solvents at $T=353 \mathrm{~K}$

\begin{tabular}{|c|c|c|c|c|c|}
\hline \multirow{2}{*}{ Solvent } & \multicolumn{4}{|c|}{ Area per molecule of diperoxide $S_{0}, \AA^{2}$} & \multirow{2}{*}{$\frac{k \cdot 10^{5}, \mathrm{~s}^{-}}{\text {DP V }}$} \\
\hline & DP III & DP XI & DP V & DP X & \\
\hline Acetone & 12.0 & - & 31.0 & 14.5 & 31.9 \\
\hline Dioxane & 13.0 & - & 26.0 & 20.0 & 37.2 \\
\hline Benzene & 31.5 & 15.6 & 40.0 & 35.3 & 19.4 \\
\hline Toluene & 30.5 & 21.6 & 43.0 & 31.3 & 17.4 \\
\hline Chloroform & 42.0 & 14.0 & 72.0 & 46.7 & 24.8 \\
\hline Ethylacetate & 46.5 & 10.3 & 37.0 & 52.7 & 24.7 \\
\hline Tetrachloromethane & 50.0 & 36.3 & 68.0 & 54.7 & 10.8 \\
\hline
\end{tabular}


The results of calculations of physical-chemical parameters for diperoxide IV by semi-empirical quantum-chemical methods

\begin{tabular}{|c|c|c|c|c|c|c|c|}
\hline Method & $\Delta_{f} H^{298}, \mathrm{~kJ} / \mathrm{mol}$ & $\mu, \mathrm{D}$ & $E_{\text {HOMO }}, \mathrm{eV}$ & $E_{\text {LUMO }}, \mathrm{eV}$ & $\eta, \mathrm{eV}$ & $S, \AA^{2}$ & $V, \AA^{3}$ \\
\hline AM1 & -1038.1 & 5.089 & -11.089 & 0.348 & 5.719 & 395.2 & 426.64 \\
\hline PM3 & -1106.9 & 3.914 & -11.440 & -0.760 & 5.600 & 398.26 & 440.37 \\
\hline PM5 & -1044.7 & 1.992 & -10.717 & -1.133 & 4.792 & 393.32 & 432.86 \\
\hline PM6 & -1044.7 & 1.993 & -10.717 & -1.133 & 4.792 & 393.32 & 432.87 \\
\hline MNDO & -986.9 & 3.419 & -11.041 & 0.358 & 5.699 & 413.54 & 446.11 \\
\hline RM1 & -1079.1 & 6.073 & -11.018 & 0.453 & 5.736 & 393.79 & 426.75 \\
\hline
\end{tabular}

Note: the experimental value $\Delta_{f} H^{298} *=-1206.9 \mathrm{~kJ} / \mathrm{mol}$ is thermochemically determined

Table 3

The results of the calculation of physical and chemical parameters of investigated diperoxides by semiempirical method RM1

\begin{tabular}{|c|c|c|c|c|c|c|c|c|}
\hline Diperoxide & $-\Delta_{f} H^{298}, \mathrm{~kJ} / \mathrm{mol}$ & $-\Delta_{f} H^{298 *}, \mathrm{~kJ} / \mathrm{mol}$ & $I_{x}, \mathrm{eV}$ & $E_{\text {HOMO }} \mathrm{eV}$ & $E_{\text {LUMO}}, \mathrm{eV}$ & $\eta, \mathrm{eV}$ & $S, \AA^{2}$ & $V, \AA^{3}$ \\
\hline I & 1243.6 & 1365.0 & 11.088 & -11.088 & 0.062 & 5.575 & 565.8 & 599.2 \\
\hline II & 1267.4 & 1347.6 & 11.116 & -11.116 & 0.267 & 5.692 & 585.6 & 627.9 \\
\hline III & 1004.1 & 1080.1 & 11.290 & -11.290 & 0.773 & 6.032 & 291.2 & 294.3 \\
\hline IV & 1079.1 & 1206.9 & 11.018 & -11.018 & 0.454 & 5.736 & 393.8 & 426.8 \\
\hline V & 1240.4 & 1406.9 & 10.663 & -10.663 & 0.387 & 5.525 & 554.2 & 635.5 \\
\hline VI & 1046.3 & 1161.3 & 11.212 & -11.212 & 0.508 & 5.860 & 356.0 & 381.7 \\
\hline VII & 1063.0 & 1206.1 & 10.975 & -10.975 & 0.540 & 5.758 & 358.9 & 429.3 \\
\hline VIII & 1364.7 & 1488.1 & 11.061 & -11.061 & 0.499 & 5.780 & 673.1 & 748.2 \\
\hline IX & 693.2 & - & 9.913 & -9.913 & -0.633 & 4.640 & 395.1 & 435.4 \\
\hline X & 1076.7 & - & 10.340 & -10.340 & -0.936 & 4.702 & 536.5 & 662.9 \\
\hline XI & 1214.7 & - & 11.179 & -11.179 & 0.818 & 5.999 & 487.7 & 510.0 \\
\hline
\end{tabular}

Note: * thermochemical data [11]

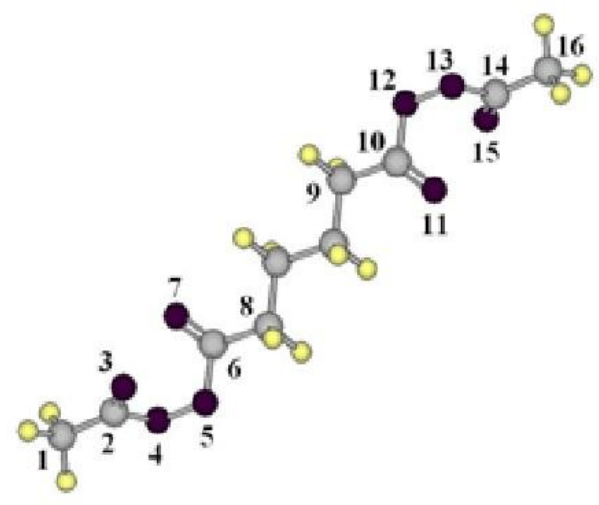

Fig. 5. The optimal geometrical structure of diperoxide III

The physic-chemical parameters for the atoms that are part of the $\mathrm{O}-\mathrm{O}$ groups and are located near them were calculated. The reactivity of the diperoxide molecules is due to the presence of peroxide groups in their composition. The numbers of heavy atoms $(\mathrm{C}$ and $\mathrm{O})$ are shown in Fig. 5. The parameters of carbon atoms, which are in positions away from peroxide groups, are practically the same. For diperoxides III, VI and IX, at the ends of which the $\mathrm{CH}_{3}$ group or $\mathrm{C}_{6} \mathrm{H}_{5}$ phenyl group are located, the constant of the thermal decay rate is lower than for all other compounds, where the final radical is large. The calculation of charges on heavy atoms $(\mathrm{C}$ and O) in the molecules of diperoxides indicates that. Thus, for the DP at the ends of the molecule there is the $\mathrm{CH}_{3}$ group (III, VI). The numerical value of the charge on atoms 1 and 16 is $(-0.224)-(-0.253)$. For all other compounds at the ends of which the molecules contain longer hydrocarbon radicals, the value is slightly lower and lies within (-0.151)-(-0.183) (Table 4). In the case of compound IX, the stabilizing effect of the phenyl radical is explained by the coupling effect of the electrons of the peroxide group and the substituent. The length of the peroxide bonds in the molecules of the studied DPs are close (1.3640-1.4139 $\AA$ ). The length of the $\mathrm{O}-\mathrm{O}$ bond in crystalline benzoyl peroxide is $1.46 \AA$ according to the literary data. The length of the connection of $\mathrm{C}-\mathrm{O}$ in the carbonyl group of DP, containing aliphatic radicals, is the same and equal to $1.2093-1.2205 \AA$. 
Table 4

The charges on atoms by Mulliken for the studied diperoxides

\begin{tabular}{|c|c|c|c|c|c|c|c|c|}
\hline \multirow{2}{*}{ Atom } & \multicolumn{8}{|c|}{ Diperoxide } \\
\hline & I & II & III & VI & VIII & IX & $\mathbf{X}$ & XI \\
\hline $\mathrm{C}(1)$ & -0.183 & -0.179 & -0.227 & -0.253 & -0.175 & -0.163 & -0.155 & -0.157 \\
\hline $\mathrm{C}(2)$ & 0.330 & 0.328 & 0.334 & 0.342 & 0.327 & 0.367 & 0.330 & 0.334 \\
\hline $\mathrm{O}(3)$ & -0.280 & -0.288 & -0.313 & -0.288 & -0.291 & -0.318 & -0.313 & -0.321 \\
\hline $\mathrm{O}(4)$ & -0.119 & -0.122 & -0.154 & -0.117 & -0.116 & -0.152 & -0.157 & -0.139 \\
\hline $\mathrm{O}(5)$ & -0.150 & -0.152 & -0.118 & -0.155 & -0.156 & -0.115 & -0.111 & -0.136 \\
\hline $\mathrm{C}(6)$ & 0.316 & 0.325 & 0.330 & 0.324 & 0.322 & 0.337 & 0.361 & 0.334 \\
\hline $\mathrm{O}(7)$ & -0.297 & -0.310 & -0.285 & -0.313 & -0.310 & -0.295 & -0.275 & -0.322 \\
\hline $\mathrm{C}(8)$ & -0.152 & -0.162 & -0.183 & -0.158 & -0.159 & -0.163 & -0.114 & -0.158 \\
\hline $\mathrm{C}(9)$ & -0.144 & -0.103 & -0.155 & -0.154 & -0.176 & -0.153 & -0.097 & -0.158 \\
\hline$C(10)$ & 0.324 & 0.324 & 0.334 & 0.331 & 0.328 & 0.334 & 0.361 & 0.334 \\
\hline $\mathrm{O}(11)$ & -0.289 & -0.310 & -0.320 & -0.320 & -0.288 & -0.315 & -0.274 & -0.322 \\
\hline $\mathrm{O}(12)$ & -0.158 & -0.151 & -0.138 & -0.135 & -0.117 & -0.137 & -0.130 & -0.136 \\
\hline $\mathrm{O}(13)$ & -0.115 & -0.120 & -0.137 & -0.138 & -0.152 & -0.129 & -0.135 & -0.139 \\
\hline$C(14)$ & 0.324 & 0.334 & 0.345 & 0.346 & 0.321 & 0.377 & 0.337 & 0.334 \\
\hline $\mathrm{O}(15)$ & -0.280 & -0.287 & -0.317 & -0.321 & -0.309 & -0.335 & -0.321 & -0.321 \\
\hline$C(16)$ & -0.183 & -0.174 & -0.224 & -0.224 & -0.154 & -0.153 & -0.151 & -0.157 \\
\hline
\end{tabular}

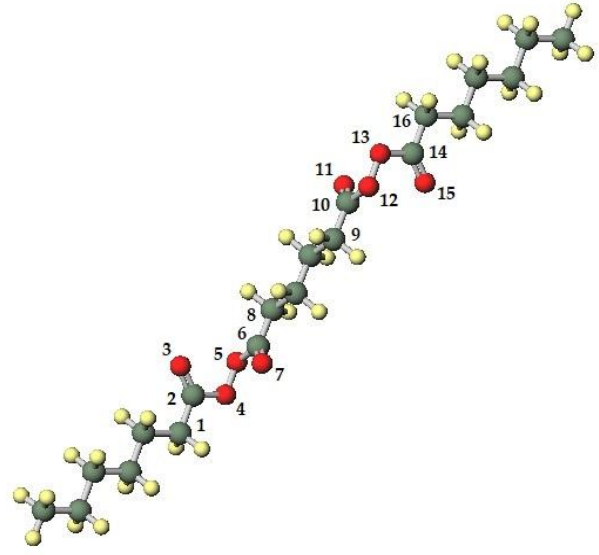

a)

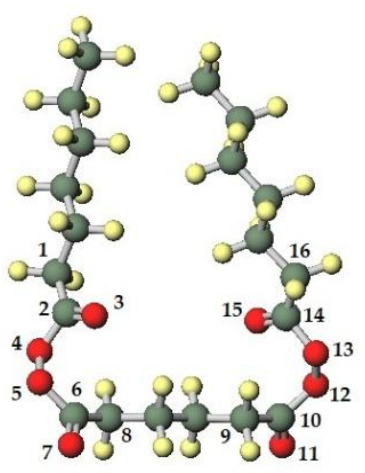

c)

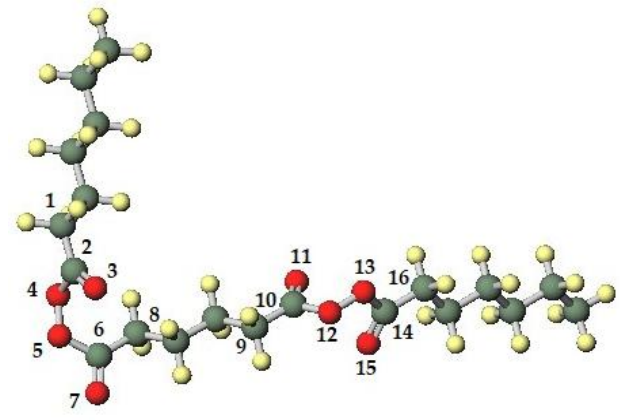

b)

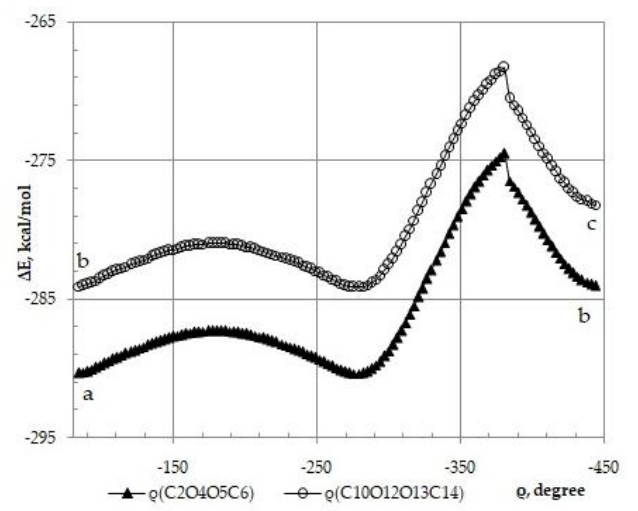

d)

Fig. 6. Conformational states of the DP XI molecule: the two-dimensional gaseous state (a); film in the expanded liquid state (b); film in a condensed state (c). The paths of conformational transitions when the torsion angles $(\rho)$ of the groups $\mathrm{C}(2) \mathrm{O}(4) \mathrm{O}(5) \mathrm{C}(6)$ and $\mathrm{C}(10) \mathrm{O}(12) \mathrm{O}(13) \mathrm{C}(14)$ are changed (d) 
All four carbonyl groups in compound IX have the largest length of $1.2550 \AA$. The length between carbon atoms and oxygen in carbonyl groups is $1.2255 \AA$ for a DP containing a phenyl nucleus between the peroxide groups $(\mathbf{X})$.

Both peroxide groups in the molecule of DP have the same reactivity. The rigidity $(\eta)$ of the studied DPs is low (Tables 2 and 3). That indicates the possibility of reactions of these compounds with both electrophilic and nucleophilic reagents.

The solvent affects both the nature of the isotherms and the extrapolated values of the areas corresponding to the molecule in the monolayer. The data obtained from the nature of most isotherms belongs to the condensed type.

The conformational analysis of the DP XI was performed by changing the placement of the terminal radicals $R_{1}$ by rotating around the $\mathrm{O}-\mathrm{O}$ axis of the peroxide groups. In the main state, the diperoxide molecule is placed planarly on the water-air interface and is in a two-dimensional gaseous state (Fig. 6a). Peroxide groups $-\mathrm{C}(\mathrm{O})-\mathrm{O}-\mathrm{O}-\mathrm{C}(\mathrm{O})$ - are located on the surface of the water. The energy of the molecule at the same time is minimal.

With an increase in surface pressure, one of the radicals $R_{1}$ is displaced from the phase separation. Due to the change in the torsion angle $\mathrm{C}(2) \mathrm{O}(4) \mathrm{O}(5) \mathrm{C}(6)$, from $\left(-84^{\circ}\right)$ to $\left(-444^{\circ}\right)$ the position of the carbonyl groups $\mathrm{C}(2)=\mathrm{O}(3)$ and $\mathrm{C}(6)=\mathrm{O}(7)$, while the energy of the molecule increases. Fig. $6 \mathrm{~b}$ depicts a peroxide molecule for this case, and Fig. 6d shows the transition path from the state (a) to the state (b).With further increase of surface pressure from the surface of the phase separation, the second radical $R_{1}$ is superseded by changing the torsion angle $\mathrm{C}(10) \mathrm{O}(12) \mathrm{O}(13) \mathrm{C}(14)$ from $\left(-84^{\circ}\right)$ to $\left(-444^{\circ}\right)$; the position of the carbonyl groups $\mathrm{C}(10)=\mathrm{O}(11)$ and $\mathrm{C}(14)=\mathrm{O}(15)$ changes as well (Fig. 6c). The energy of the DP XI molecule increases even more, and the path of this change is shown in Fig. 6d.

\section{Conclusions}

The monolayers of 11 diperoxides of the different structures were formed on the water-air interface using the Langmuir method. The solvent affects both the nature of the isotherms and the extrapolated values of the areas corresponding to the molecule in the monolayer. The nature of most isotherms belongs to the condensed type.

From the investigation of the behavior of diperoxide monomolecular films on the water-air interface a different conformation of the molecules in the monolayer was found. Diperoxides with small radicals $\mathrm{CH}_{3}-\left(\mathrm{CH}_{2}\right)_{m^{-}}$, form on the surface condensed monolayers. The radical located between peroxide groups
$-\left(\mathrm{CH}_{2}\right)_{n}-$ is stiff. Hydrophilic peroxide groups are located on the surface of the water, and hydrophobic hydrocarbon radicals can squeeze from surface to air.

The conformational analysis of the studied peroxides indicates that the area of the molecule at the interface takes different values. The correspondence of theoretically calculated and experimental data indicates the correctness of the used semiempirical quantum-chemical methods. The numerical values of the calculated areas are correlated with the corresponding values found for the molecules of the diperoxides in the monolayer. The results of this study may be useful for predicting the behavior of diperoxide on the phase boundary in heterogeneous processes with the participation of these compounds.

\section{References}

[1] Voronov S., Varvarenko S.: Peroxidovmisni Makromolekuly na Mezhi Rozdilu Phaz. Lviv Polytech. Publ. House, Lviv 2011.

[2] Antonovskii V., Khursan S.: Russ. Chem. Rev., 2003, 72, 939.

https://doi.org/10.1070/RC2003v072n11ABEH000749

[3] Arslanov V.: Russ. Chem. Rev., 2000, 69, 883.

https://doi.org/10.1070/RC2000v069n10ABEH000612

[4] Arslanov V.: Nanotechnologia. Kolloidnaia i

Supramolekuliarnaia Khimia. Entsiklopedicheskiy spravoschnik. Lenand 2015.

[5] Dopierała K., Rojewska M., Skrzypiec M., et al.: Liq. Cryst., 2018, 45, 351. https://doi.org/10.1080/02678292.2017.1325524

[6] Dutka V., Midyna G., Dutka Yu., Palchikova E.: Rus. J. Gen. Chem., 2018, 88, 632. https://doi.org/10.1134/S1070363218040047

[7] Antonovskii V., Buzulanova M.: Analiticheskaia Khimia Organicheskich Peroxydnykh Soedinenii. Moskva 1978.

[8] Wu Y., Liu Z., Zhou S. et al.: J. Electrochem. Soc., 2019, 166, H542. https://doi.org/10.1149/2.0371913jes

[9] Stewart J.: Program Package MOPAC2016.

http://www.openmopac.net

[10] Senda N.: Program Package Winmostar. http://winmostar.com [11] Van-Chin-Syan Yu., Pavlovskii Yu., Gerasimchuk S., Dutka

V.: Rus. J. Phys. Chem. A. 2012, 86, 527.

https://doi.org/10.1134/S0036024412040292

Received: July 16, 2020 / Revised: August 18, 2020 / Accepted: October 02, 2020

\section{МОНОМОЛЕКУЛЯРНІ ПЛІВКИ ОРГАНІЧНИХ ДІАЦИЛЬНИХ ДИПЕРОКСИДІВ НА МЕЖІ РОЗДІЛУ ФАЗ ВОДА-ПОВІТРЯ}

Анотація. Вивчено мономолекулярні плівки діацильних дипероксидів на межсі розділу фаз вода-повітря. На їх поведінку впливає структура молекули та розчинник. Числові значення площ молекул, які екстрапольовані на нульовий тиск відрізняються, щзо вказує на різну конформацію молекул в моношарі. Квантово-хімічними методами проведено розрахунки конформаційних станів дипероксидів. Експериментальні дані та квантово-хімічні розрахунки узгоджуються між собою.

Ключові слова: діацильні дипероксиди, мономолекулярні шари, квантово-хімічні розрахунки, конформачії. 